\title{
Antiproliferative and Antibacterial Activities of Cirsium scabrum from Tunisia
}

\author{
Ramla Sahli, ${ }^{1,2}$ Céline Rivière, ${ }^{1}$ Cédric Dufloer, ${ }^{1}$ Claire Beaufay, ${ }^{3}$ \\ Christel Neut, ${ }^{4}$ Joanne Bero, ${ }^{3}$ Thierry Hennebelle, ${ }^{1}$ Vincent Roumy, ${ }^{1}$ Riadh Ksouri, ${ }^{2}$ \\ Joelle Quetin-Leclercq, ${ }^{3}$ and Sevser Sahpaz ${ }^{1}$ \\ ${ }^{1}$ Institut Charles Viollette (EA 7394), Université de Lille, 59000 Lille, France \\ ${ }^{2}$ The Laboratory of Aromatic and Medicinal Plants, Biotechnology Centre of Borj-Cédria (CBBC), Hammam-lif, Tunisia \\ ${ }^{3}$ Pharmacognosy Research Group, Louvain Drug Research Institute, Université Catholique de Louvain, Avenue E. Mounier, \\ No. 72, B01.72.03-1200 Brussels, Belgium \\ ${ }^{4}$ UDSL, INSERM U995, UFR Pharmacie, 59000 Lille, France
}

Correspondence should be addressed to Céline Rivière; celine.riviere-3@univ-lille2.fr

Received 22 March 2017; Accepted 6 June 2017; Published 12 July 2017

Academic Editor: Ken Yasukawa

Copyright (C) 2017 Ramla Sahli et al. This is an open access article distributed under the Creative Commons Attribution License, which permits unrestricted use, distribution, and reproduction in any medium, provided the original work is properly cited.

\begin{abstract}
Several Cirsium species are known for their uses in traditional medicine and consequently are studied for their phytochemical content and their biological activities. In the framework of a previous study conducted on eight extremophile plants from Tunisia, we highlighted that the crude methanolic extract of C. scabrum, a not investigated thistle, showed moderate but quite selective

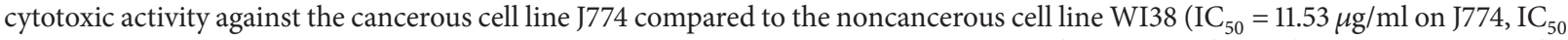
$=29.89 \mu \mathrm{g} / \mathrm{ml}$ on WI38, and selectivity index $=2.6$ ). In the current study, the partitions of the leaves of C. scabrum were analyzed for their antiproliferative activity on the same cell lines. From the most active petroleum ether partition, we isolated four triterpenoids including lupeol, taraxasterol acetate, and a (1:1) mixture of 25 -hydroperoxycycloart-23-en-3 $\beta$-ol and 24 -hydroperoxycycloart25 -en-3 $\beta$-ol. These two cycloartane-type triterpenoids are mostly responsible for this cytotoxic activity. On the other hand, the antimicrobial potential of this plant was also evaluated against 36 microorganisms. The moderate antibacterial activity against 6 Staphylococcus aureus and 2 Dermabacter hominis strains is mainly attributed to the butanol partition whose major compounds are glycosides of flavones.
\end{abstract}

\section{Introduction}

The genus Cirsium (thistle), belonging to the Asteraceae family, is well distributed around the world. About 200 Cirsium species are distributed in Europe, North Africa, Asia, and North and Central America [1]. In agriculture, Cirsium species are often considered as invasive weeds against which massive means of control are deployed. By contrast, some species are easily cultivated by communities in dry steppes of Mongolia where fruits and vegetables are not easily afforded [2]. In some countries, such as in Turkey, some Cirsium species are considered as edible plants [3]. Different parts can be consumed, such as stems, roots, and dethroned young leaves [4]. Some species of the genus Cirsium are also used as medicinal plants in the traditional medicine of several countries. In some European countries, the tea prepared from the leaves of some Cirsium species possesses therapeutic virtues. It is the case in Central Italy where the decoction of the leaves of Cirsium arvense is used to treat abdominal pains and intestinal disturbances. The species is also frequently used as an emergency haemostatic for wounds [5]. The roots or the entire plants of more than ten species are used in China for the treatment of various ailments including hemorrhaging, jaundice, and gastrointestinal disorders [6]. According to literature, these traditional uses led to the consideration of the phytochemistry and the biological activities of some species. Cirsium species contain a variety of natural products including flavonoids, phenolic acids, 
lignans, sesquiterpenoids, triterpenoids, sterols, alkaloids, acetylenes, polyacetylenes, hydrocarbons, and a few other compounds [7]. Flavonoids and their glycosides are the main secondary metabolites of Cirsium species [6]. The compounds isolated from Cirsium species and extracts show many different biological activities including antimicrobial, antioxidant, antidiabetic, anti-inflammatory, vasorelaxant, astringent, hepatoprotective, and anticancer activities [8].

Cirsium scabrum (Poir.) Bonnet \& Barratte is a tall thistle native of the Mediterranean region [4]. To our knowledge, no reports on the uses of this plant in the traditional medicine, on its chemical composition, and on its biological activities have been provided in the literature so far. In a previous study conducted on eight extremophile plants from Tunisia, we highlighted that the crude methanolic extract of C. scabrum showed moderate but quite selective cytotoxic activity against $\mathrm{J} 774$ compared to WI38 $\left(\mathrm{IC}_{50}=11.53 \mu \mathrm{g} / \mathrm{ml}\right.$ on $\mathrm{J774}, \mathrm{IC}_{50}=29.89 \mu \mathrm{g} / \mathrm{ml}$ on WI38, and selectivity index = 2.6) [9]. In addition, the therapeutic uses attributed to several Cirsium species prompt us to explore in more depth the cytotoxic effect of the leaves of C. scabrum and to identify the compounds responsible for this activity using a bioguided fractionation approach. As several Cirsium species demonstrate an antimicrobial potential [7], we used the same approach to evaluate the antimicrobial activity of this species against a panel of 36 microorganisms and to identify the bioactive natural products.

\section{Material and Method}

2.1. General Experimental Procedures. For the extraction and fractionation, synthesis grade methanol $(\mathrm{MeOH})$, petroleum ether $(\mathrm{PE})$, methylene chloride $\left(\mathrm{CH}_{2} \mathrm{Cl}_{2}\right)$, and cyclohexane were furnished by VWR chemicals (Fontenay-sous-Bois, France), whereas ethyl acetate (EtOAc) and n-heptane were obtained from Carlo Erba (Val-de-Reuil, France). Toluene was purchased from Fisher Scientific (Illkirch, France). Water (W) was bidistilled. All organic solvents for Centrifugal Partition Chromatography (CPC) purification were of HighPressure Liquid Chromatography (HPLC) grade except for the n-heptane which was of synthesis grade (Carlo Erba, Val-de-Reuil, France). Ethyl acetate (EtOAc) and methanol $(\mathrm{MeOH})$ were purchased from Fisher Scientific (Illkirch, France). Water was purified using Millipore Integral 5 (France) water purification system with a resistivity of not less than $18 \mathrm{M} \Omega \cdot \mathrm{cm}^{-1}$. The chloroform-d6 and MeOD for Nuclear Magnetic Resonance (NMR) experiments were obtained from Euriso-Top (Gif-sur-Yvette, France).

Analytical Thin Layer Chromatography (TLC) was performed on precoated silica gel $60 \mathrm{~F}(0.25 \mathrm{~mm}$, Merck, Germany) and the spots were visualized under UV (254 and $365 \mathrm{~nm}$ ) before being sprayed with a solution of sulfuric anisaldehyde and heating at $100^{\circ} \mathrm{C}$ for $10 \mathrm{~min}$. Silica gel 60 (63-200 $\mu \mathrm{m}$, Macherey-Nagel, Germany) and silica gel $60 \mathrm{H}$ ( $<63 \mu \mathrm{m}$, Macherey-Nagel, Germany) were used for column chromatography.

Analytical HPLC was carried out using a Shimadzu binary LC-10AS pump, a SCL-10A UV-visible detector, and a Vision HT Basic C18 (5 $\mu \mathrm{m}, 4 \mathrm{~mm}$ i.d. $\times 250 \mathrm{~mm})$ column (Grace, Epernon, France). Preparative HPLC was performed using a Shimadzu HPLC system equipped with a LC20AP binary high-pressure pump, a SPD-M20A photodiode array detector, and a VisionHT Basic C18 $(5 \mu \mathrm{m}, 22 \mathrm{~mm}$ i.d. $\times 250 \mathrm{~mm})$ column. The mobile phase was composed of $0.01 \%$ formic acid in water (solvent A) and acetonitrile (ACN) (solvent B). For analytical HPLC analysis, $20 \mu \mathrm{l}$ of extract $(10 \mathrm{mg} / \mathrm{ml}$ in $\mathrm{MeOH})$ was injected at $1 \mathrm{ml} / \mathrm{ml}$, whereas, for preparative HPLC analysis, $200 \mathrm{mg}$ of extract solubilized in $\mathrm{MeOH}$ was injected at $14 \mathrm{ml} / \mathrm{min}$. The wavelength used was $254 \mathrm{~nm}$. For both analyses, the following gradient elution program was used: $10-25 \%$ B (0-15 min), 25-26.5\% B (15-20 min), 26.5-34.75\% B (20-25 min), 34.75\% B (25-28 min), 34.75-35.12\% B (28-29 min), 35.12\% B (29-32 $\mathrm{min})$, and $35.12-100 \% \mathrm{~B}$ (32-35 min).

CPC was performed using an Armen instrument $250 \mathrm{~mL}$ rotor (SCPC-250-L) provided by Armen instrument (SaintAvé, France). CPC analyses were monitored using Shimadzu pump and detector.

NMR spectra were recorded on a Bruker DPX-500 spectrometer $\left({ }^{1} \mathrm{H}\right.$ and ${ }^{13} \mathrm{C} \mathrm{NMR}$ at $\left.500 \mathrm{MHz}\right)$, except for compound 2 identified on a $600 \mathrm{MHz}$ spectrometer. For triterpenoids, MS analyses were carried out using a Trace DSQ mass spectrometer (Thermo Finnigan) operating in the electron-impact mode. Samples were analyzed in a fullscan mode (100-700 amu) and were injected directly with a DEP probe. The data obtained were compared with those of the database NIST. Data acquisition and processing were performed with Xcalibur software. For flavonoids, HRMS analyses were carried out in negative mode with a range of $m / z 100-1000$, using a Thermo Fisher Scientific Exactive Orbitrap mass spectrometer equipped with an electrospray ion source. The vaporizer temperature of the source was set at $100^{\circ} \mathrm{C}$, the nitrogen sheath gas at $10-20$, and the auxiliary gas at 2-6 (arbitrary units).

2.2. Plant Material. Cirsium scabrum was collected in August 2013 in the North of Tunisia (Goubellat) and was identified at the Biotechnology Centre of Borj-Cédria by Dr. Abderrazak Smaoui. A voucher specimen (181) was deposited at the Herbarium of the Laboratory of Extremophile Plants at the Biotechnology Centre of Borj-Cédria.

\subsection{Preparation of the Methanolic Crude Extract of C. scabrum} Leaves. $260.8 \mathrm{~g}$ of C. scabrum leaves was dried at $25^{\circ} \mathrm{C}$ for a week and then powdered. Extraction was carried out by maceration at room temperature $(\mathrm{MeOH}, 15 \mathrm{ml}$ per $\mathrm{g}$ of powder, $3 \times 48 \mathrm{~h}$ ). After filtration, extract was dried in vacuum at $35^{\circ} \mathrm{C}$ and lyophilized to afford $22.17 \mathrm{~g}$ of crude methanolic extract (yield $=8.5 \%$ ).

2.4. Fractionation of the Methanolic Crude Extract of $C$. scabrum Leaves. The crude methanolic extract of C. scabrum leaves $(\mathrm{CS}=12 \mathrm{~g}$ ) was suspended in water $(20 \mathrm{ml})$ and partitioned with $\mathrm{PE}, \mathrm{CH}_{2} \mathrm{Cl}_{2}$, EtOAc, and butanol $(10 \times$ $60 \mathrm{ml}$ ). Partitions were concentrated at $35^{\circ} \mathrm{C}$ under reduced pressure to give $\mathrm{PE}$ partition $(\mathrm{CSPE}=0.84 \mathrm{~g}), \mathrm{CH}_{2} \mathrm{Cl}_{2}$ partition $(\mathrm{CSMC}=1.46 \mathrm{~g})$, EtOAc partition $(\mathrm{CSEA}=1.03 \mathrm{~g})$, 
and butanol partition $(\mathrm{CSBt}=2.72 \mathrm{~g})$. The remaining aqueous partition was freeze-dried and lyophilized $(\mathrm{CSW}=5.16 \mathrm{~g})$.

2.5. Isolation of Compounds from the CSPE Partition. $2 \mathrm{~g}$ of the CSPE partition (obtained after two successive extractions and fractionations) was subjected to column chromatography (CC) on silica gel $60(63-200 \mu \mathrm{m})$ using a gradient of heptane/EtOAc (100:0 to $70: 30)$ to give seven fractions (CSPE1-CSPE7) based on their TLC behaviour (heptane/EtOAc, $7: 3$ ). Compound 1 ( $21.9 \mathrm{mg}$ ) was isolated by this process (heptane/EtOAc, $95: 5$ ).

Compound $2(1.5 \mathrm{mg})$ was isolated from the combined fractions CSPE1 and CSPE2 $(346.3 \mathrm{mg})$ by a silica gel $60 \mathrm{H} \mathrm{CC}$, eluted with $\mathrm{PE} / \mathrm{CH}_{2} \mathrm{Cl}_{2}(25: 5)$.

Preparative Centrifugal Partition Chromatography (CPC) was carried out to isolate compounds from the most active combined fractions CSPE4 and CSPE5. CPC separation was conducted using a quaternary biphasic solvent system: Arizona X (n-Hept/EtOAc/MeOH/ $\mathrm{H}_{2} \mathrm{O}$, $9: 1: 9: 1$ ). Ten quaternary biphasic solvent systems (Arizona) were tested in order to choose the optimal system [10]. The two phases (aqueous and organic) of Arizona X system were prepared. The rotor was entirely filled at $30 \mathrm{ml} / \mathrm{min}$ and $500 \mathrm{rpm}$ with the aqueous stationary phase $(400 \mathrm{~mL})$ in the ascending mode. The rotation speed was increased to $1600 \mathrm{rpm}$ and the organic mobile phase was pumped into the column in ascending mode at a flow-rate of $8 \mathrm{ml} / \mathrm{min}$. Separation was performed using $400 \mathrm{mg}$ of combined partitions CSPE4/CSPE5, in ascending mode for $25 \mathrm{~min}$, and then switched to descendant mode for $27 \mathrm{~min}$. Fractions of $8 \mathrm{ml}$ were collected every $\mathrm{min}$ by a Gilson FC 204fraction collector (52 subfractions: X1-X52). Fractions were checked by TLC developed with heptane/EtOAc $(7: 3)$. CPC analysis allowed the direct purification of a $(1: 1)$ mixture of compounds $\mathbf{3 a}$ and $\mathbf{3 b}$ (X30-X33: $9.6 \mathrm{mg})$.

2.6. Isolation of Compounds from the CSBt Partition. Major compounds of the CSBt partition (compounds $\mathbf{4 a} / \mathbf{4} \mathbf{b}$ and 5) were isolated by preparative HPLC using the following gradient elution program: $10-25 \%$ B $(0-15 \mathrm{~min})$, $25-26.5 \%$ B (15-20 min), 26.5-34.75\% B (20-25 min), 34.75\% B (25-28 min), $34.75-35.12 \%$ B (28-29 min), $35.12 \%$ B (29-32 min), and $35.12-100 \%$ B (32-35 min). From $200 \mathrm{mg}$ of the CSBt partition, $8.04 \mathrm{mg}$ of compound $4 \mathbf{a} / 4 \mathbf{b}$ and $5.96 \mathrm{mg}$ of compound 5 were obtained.

\subsection{Cytotoxicity Assays}

Cell Culture. The cytotoxicity was evaluated on two cell lines: J774 (macrophage-like cell line, derived from BALB/c murine reticulum cell sarcoma) and WI38 (human normal fibroblastlike lung cell line), using the tetrazolium salt MTT [3(4,5-dimethylthiazol-2-yl)-2,5-diphenyltetrazolium bromide (Sigma)] colorimetric method, as described by Bero et al. [11]. J774 cells were cultivated in a humidified atmosphere with 5\% $\mathrm{CO}_{2}$ at $37^{\circ} \mathrm{C}$ in RPMI 1640 medium (Life Technologies, Paisley, UK) containing $2 \mathrm{mM}$ L-glutamine supplemented with $10 \%$ heat-inactivated fetal bovine serum (Life Technologies) and penicillin-streptomycin $(100 \mathrm{UI} / \mathrm{ml})$. WI38 cells were cultivated in a humidified atmosphere with $5 \% \mathrm{CO}_{2}$ at $37^{\circ} \mathrm{C}$ in DMEM medium (Life Technologies) containing $4 \mathrm{mM} \mathrm{L-}$ glutamine, $1 \mathrm{mM}$ sodium pyruvate supplemented with $10 \%$ heat-inactivated fetal bovine serum (Life Technologies), and penicillin-streptomycin $(100 \mathrm{UI} / \mathrm{ml})$.

Cytotoxicity Assay. Briefly, WI38 or J774 cells were seeded in 96-well plates (5000 cells/well/180 $\mu \mathrm{l}$ medium or $2.8 \times$ $10^{4}$ cells $/ \mathrm{ml}$ ). After $24 \mathrm{~h}$, cells were treated with $20 \mu \mathrm{l}$ of crude extract and partitions solutions in a fixed concentration of $50 \mu \mathrm{g} / \mathrm{ml}$ to calculate cell viability percentage. When an extract or a partition presents a percentage inferior to $50 \%$, an $\mathrm{IC}_{50}$ is calculated with a range of concentration between 0.023 and $50 \mu \mathrm{g} / \mathrm{ml}$ obtained from a $20 \mathrm{mg} / \mathrm{ml}$ DMSO stock solution diluted in fresh medium. In the same way, fractions (CSPE1 to CSPE7) obtained from the most active partition (CSPE) and purified compounds were tested at two fixed concentrations of 5 and $20 \mu \mathrm{g} / \mathrm{ml}$. This time, an $\mathrm{IC}_{50}$ is calculated for cell viability percentages inferior to $50 \%$ at $20 \mu \mathrm{g} / \mathrm{ml}$ with a range of concentration between 0.01 and $20 \mu \mathrm{g} / \mathrm{ml}$ obtained as cited above. After $72 \mathrm{~h}$, the medium was replaced by $100 \mu \mathrm{l}$ of a $10 \%$ MTT solution $(3 \mathrm{mg} / \mathrm{ml}$ in PBS) in medium. After $45 \mathrm{~min}$, the medium was removed again and $100 \mu \mathrm{l}$ of DMSO was added to solubilize formed formazan crystals. Absorbance was recorded at $570 \mathrm{~nm}$ and $620 \mathrm{~nm}$. Each sample was tested in eight serial threefold dilutions in 96-well microtiter plates, at least three wells per concentration in duplicate. Camptothecin (Sigma) was used as positive control (concentration range: $25-0.00032 \mu \mathrm{g} / \mathrm{ml}$ ). The highest concentration of solvent to which the cells were exposed was $0.25 \%$, which was shown to be nontoxic.

Cell viability $\%=[A T / A N T] \times 100$, with $A$ : absorbance, NT: control cells, and $T$ : treated cells.

2.8. Antimicrobial Assay. The antimicrobial activity of crude extract and partitions was evaluated against 36 pathogenic microorganisms (22 Gram-positive bacteria, 13 Gramnegative bacteria, and 1 yeast) according to Mahamodo et al. [12]. The 36 microorganisms were grown overnight at $37^{\circ} \mathrm{C}$ on sloping Mueller-Hinton ( $\left.\mathrm{MH}\right)$ agar medium. Briefly, the bacteria were diluted with Ringer's Cysteine (RC) solution to obtain $10^{6}$ bacteria/ml. In Petri dishes, $19 \mathrm{ml}$ MH 2 agar was supplemented with $1 \mathrm{ml}$ of stock solution of crude extract or partitions $(12.5 \mathrm{mg} / \mathrm{ml}$ to $0.39 \mathrm{mg} / \mathrm{ml})$ or antibiotics (gentamicin, vancomycin, and amoxicillin) $\left(28 \mathrm{mg} / \mathrm{ml}\right.$ to $\left.6 \cdot 10^{-3} \mathrm{mg} / \mathrm{ml}\right)$, giving final concentrations from 625 to $19.5 \mu \mathrm{g} / \mathrm{ml}$ for the extracts and 64 to $0.03 \mu \mathrm{g} / \mathrm{ml}$ for antibiotics. Inocula of $10^{4}$ colony forming units (CFU) were spotted ultimately with a multipoint inoculator (Steers Replicator).

2.9. Statistical Analysis. Data were analyzed by GraphPad Prism 7 statistical software and presented as the mean \pm standard error of the mean. Activity differences between both cell lines were analyzed by the two-tailed nonparametric Mann-Whitney test to highlight significant toxicity. However, the two-tailed Wilcoxon signed-rank test was used to compare activity (for CSMC, CSEA, CSPE4, and CSPE5) on 
TABLE 1: In vitro cytotoxicity of the crude extract and partitions of C. scabrum leaves.

\begin{tabular}{lccc}
\hline $\begin{array}{l}\text { Crude extract } \\
\text { and partitions }\end{array}$ & $\begin{array}{c}\mathrm{WI} 38 \\
\mathrm{IC}_{50}(\mu \mathrm{g} / \mathrm{ml})\end{array}$ & $\begin{array}{c}\mathrm{J} 774 \\
\mathrm{IC}_{50}(\mu \mathrm{g} / \mathrm{ml})\end{array}$ & $\begin{array}{c}\mathrm{SI} \\
\left(\mathrm{IC}_{50} \mathrm{JI}_{38} / \mathrm{IC}_{50}\right. \\
\left.\mathrm{J}_{774}\right)\end{array}$ \\
\hline CSRW & $29.89 \pm 2.38$ & $11.53 \pm 1.07$ & $2.6^{* * *}$ \\
CSPE & $33.21 \pm 2.22$ & $12.12 \pm 0.34$ & $2.7^{* * *}$ \\
CSMC & $>50$ & $48.13 \pm 1.87$ & $>1$ \\
CSEA & $>50$ & $40.97 \pm 2.91$ & $>1.2^{*}$ \\
CSBt & $>50$ & $>50$ & $>1$ \\
CSW & $>50$ & $>50$ & $>1$ \\
Camptothecin & $0.175 \pm 0.029$ & $0.011 \pm 0.002$ & $15^{* * *}$ \\
\hline
\end{tabular}

CSRW: C. scabrum leaves crude extract; CSPE: C. scabrum leaves petroleum ether partition; CSMC: C. scabrum leaves methylene chloride partition; CSEA: C. scabrum leaves ethyl acetate partition; CSBt: C. scabrum leaves butanol partition; CSW: C. scabrum leaves water partition; camptothecin: positive control; results are expressed as mean \pm standard error of the mean (SEM) from six determinations and activity differences between cell lines are statistically defined for each partition with the Mann-Whitney or Wilcoxon signed-rank tests for comparison to the highest tested concentration $\left(p<0.05^{*}, p<0.005^{* * *}\right)$.

J774 to the maximum tested value on WI38, 50 or $20 \mu \mathrm{g} / \mathrm{ml}$, respectively. Statistical significance for all statistical tests was set at $p<0.05$.

\section{Results}

3.1. Cytotoxic Activity of Crude Methanolic Extract and Partitions of Cirsium scabrum Leaves. In a previous study [9], we showed that the cytotoxicity of the crude methanolic extract of C. scabrum leaves (CSRW) was particularly interesting. It showed, among other plant extracts tested, the highest activity on $\mathrm{J774}$ cell line $\left(\mathrm{IC}_{50}=11.53 \mu \mathrm{g} / \mathrm{ml}\right)$ and was also quite selective $\left(\mathrm{IC}_{50}=29.89 \mu \mathrm{g} / \mathrm{ml}\right.$ on WI38, selectivity index = 2.6). In this study, our objective is to identify the compounds responsible for this activity. For this purpose, the partitions of C. scabrum leaves obtained from the crude methanolic extract by liquid-liquid partitioning (CSPE, CSMC, CSEA, CSBt, and CSW) were also analyzed for their antiproliferative activity on the same cell lines (Table 1). Among all tested partitions, the petroleum ether partition (CSPE) showed the highest activity on $\mathrm{J774}$ with an $\mathrm{IC}_{50}$ value $\left(\mathrm{IC}_{50}=12.12 \mu \mathrm{g} / \mathrm{ml}\right)$ almost similar to that of the crude methanolic extract (CSRW). As CSRW, CSPE was also interesting because it showed some selectivity $\left(\mathrm{IC}_{50}=33.21 \mu \mathrm{g} / \mathrm{ml}\right.$ on WI38, selectivity index $\left.=2.7\right)$. A SI value inferior to 2 may indicate a general toxicity of an extract or a pure compound [13]. In our case, we obtained SI superior to 2 for both the crude extract CRSW and the partition CSPE with significant differences $(p<0.05)$ between both cell lines.

3.2. Cytotoxic Activity of CSPE Fractions. In view of these results, we followed our bioguided fractionation on the most active partition CSPE. The fractionation of CSPE by silica gel column chromatography produced seven fractions (CSPE1-CSPE7), based on their TLC behaviours, which were analyzed for their antiproliferative activity on both cell lines (Table 2). The highest activity was recorded for the fractions
TABLE 2: In vitro cytotoxicity of CSPE fractions.

\begin{tabular}{lccc}
\hline CSPE fractions & $\begin{array}{c}\mathrm{WI} 38 \\
\mathrm{IC}_{50}(\mu \mathrm{g} / \mathrm{ml})\end{array}$ & $\begin{array}{c}\mathrm{J} 774 \\
\mathrm{IC}_{50}(\mu \mathrm{g} / \mathrm{ml})\end{array}$ & $\begin{array}{c}\mathrm{SI} \\
\left(\mathrm{IC}_{50} \mathrm{wI38} / \mathrm{IC}_{50}\right. \\
\left.\mathrm{J}_{774}\right)\end{array}$ \\
\hline CSPE1 & $>20$ & $>20$ & $>1$ \\
CSPE2 & $>20$ & $>20$ & $>1$ \\
CSPE3 & $>20$ & $>20$ & $>1$ \\
CSPE4 & $>20$ & $13.77 \pm 1.26$ & $>1.4^{*}$ \\
CSPE5 & $>20$ & $8.96 \pm 1.09$ & $>2.2^{*}$ \\
CSPE6 & $>20$ & $>20$ & $>1$ \\
CSPE7 & $>20$ & $>20$ & $>1$ \\
Camptothecin & $0.175 \pm 0.029$ & $0.011 \pm 0.002$ & $15^{* * *}$ \\
\hline
\end{tabular}

CSPE1-CSPE7: fractions of CSPE; camptothecin: positive control; results are expressed as mean \pm standard error of the mean (SEM) from six determinations and activity differences between cell lines are statistically defined for each fraction with the Mann-Whitney or Wilcoxon signedrank tests for comparison to the highest tested concentration $\left(p<0.05^{*}\right.$, $\left.p<0.005^{* * *}\right)$.

CSPE4 and CSPE5 with $\mathrm{IC}_{50}$ values equal to 13.77 and $8.96 \mu \mathrm{g} / \mathrm{ml}$, respectively. Besides, these fractions did not show any toxicity at $20 \mu \mathrm{g} / \mathrm{ml}$, the maximum concentration tested on the noncancerous WI38 cell line, and their activity on J774 was significantly different with selectivity indices higher than 1.4 and 2.2, respectively. All other fractions were considered as nonactive $\left(\mathrm{IC}_{50} \geq 20 \mu \mathrm{g} / \mathrm{ml}\right)$.

3.3. Purification of Compounds from CSPE Partition. A rapid phytochemical screening revealed that CSPE partition is rich in terpenoids and phytosterols, while the presence of alkaloids, flavonoids, saponins, and tannins was not detected. Four compounds were purified from some CSPE fractions by silica gel column chromatography (CC) or by Centrifugal Partition Chromatography (CPC). All compounds were identified and characterized by their spectroscopic data $\left({ }^{1} \mathrm{H}\right.$ and ${ }^{13} \mathrm{C} \mathrm{NMR}, 2 \mathrm{D}$ NMR experiments) and spectra mass data and by comparisons with the literature. Compounds $\mathbf{1}$ and $\mathbf{2}$ were identified as two common triterpenoids, respectively, lupeol and taraxasterol acetate [14, 15]. Compounds $\mathbf{3} \mathbf{a}$ and $\mathbf{3} \mathbf{b}$ were identified as andissociable $(1: 1)$ mixture of two hydroperoxide cycloartane-type triterpenoids: 25 -hydroperoxycycloart-23-en-3 $\beta$-ol (3a) and 24 hydroperoxycycloart-25-en-3 $\beta$-ol $(3 \mathbf{b})[16,17]$ (Figure 1).

3.4. Cytotoxic Activity of Purified Compounds. The mixture of two cycloartane-type triterpenoids obtained from the most active fractions (combined fractions CSPE4 and CSPE5) was analyzed for their antiproliferative activity on J774 and WI38 cell lines (Table 3 ). Even if lupeol was isolated directly by CC on silica gel 60 from CSPE and not from CSPE45, we tested its activity due to data of the literature [18]. Lupeol exhibited a cytotoxic activity against the J774 cell line with an $\mathrm{IC}_{50}$ value similar to that of the CSPE partition $\left(\mathrm{IC}_{50}=12.60 \mu \mathrm{g} / \mathrm{ml}\right)$ but did not show selectivity against the 

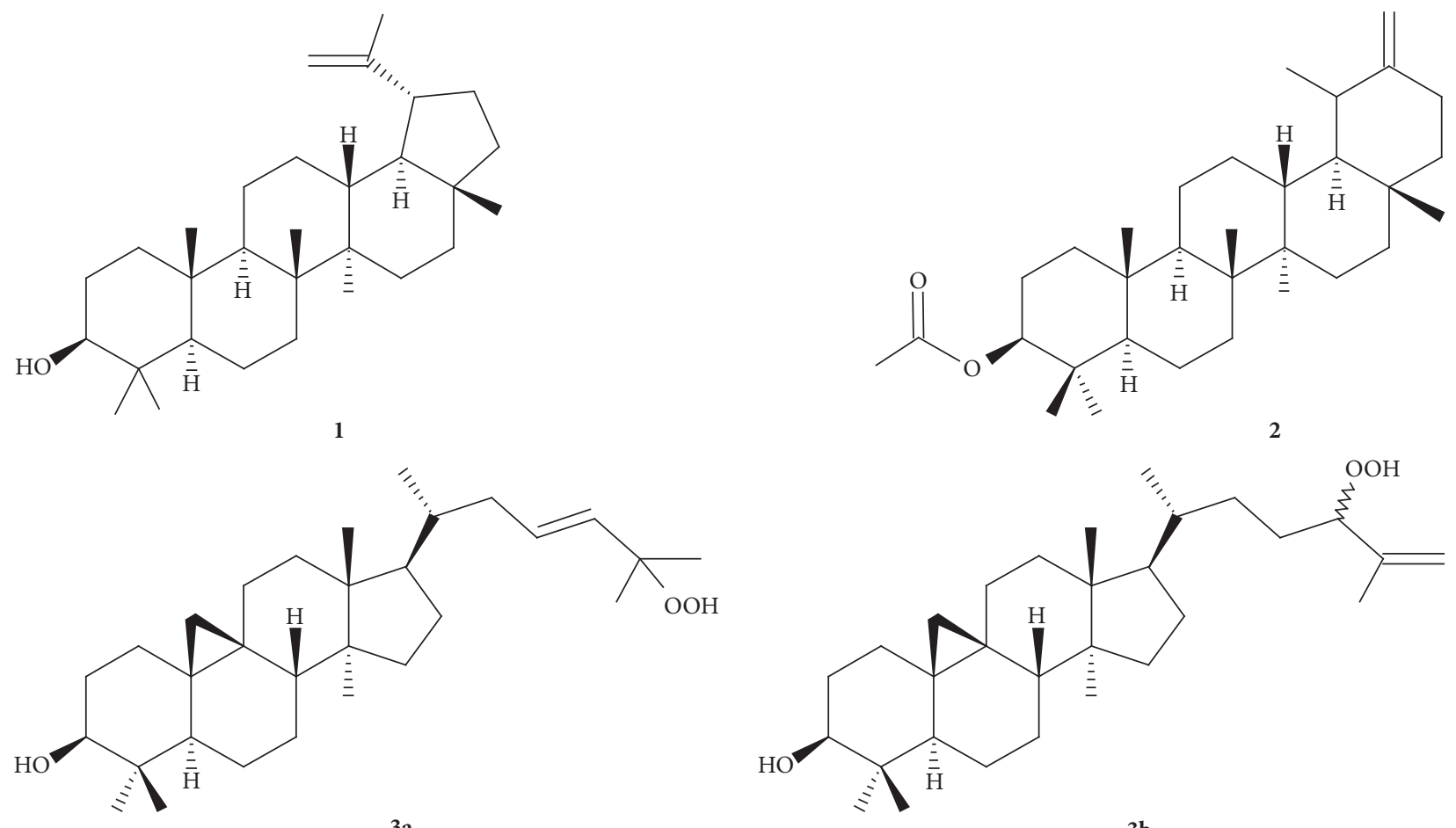

3a

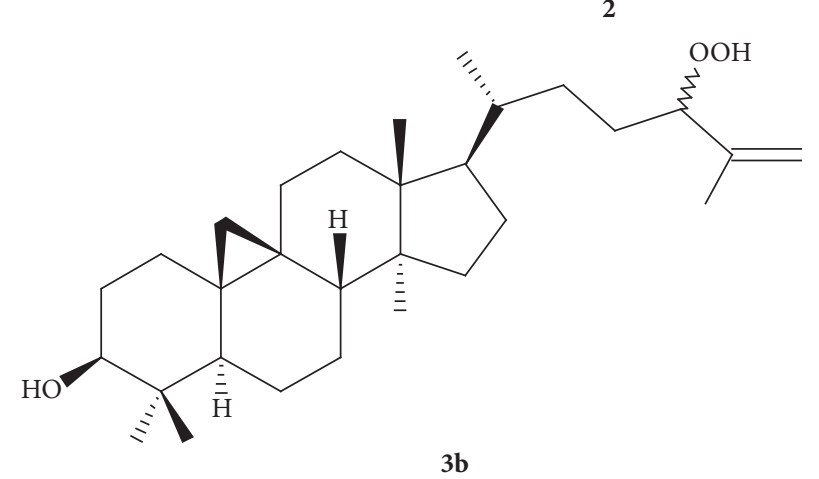<smiles>O=C(O)C1OC(Oc2cc(O)c3c(=O)cc(-c4ccc(O)c(O)c4)oc3c2)C(O)C(O)C1O</smiles><smiles>O=c1cc(-c2ccc(O)c(O)c2)oc2cc(OC3OC(CO)C(O)C(O)C3O)cc(O)c12</smiles><smiles>O=C(O)C1OC(Oc2cc(O)c3c(=O)cc(-c4ccc(O)cc4)oc3c2)C(O)C(O)C1O</smiles>

FIgURE 1: Compounds isolated from Cirsium scabrum. 
TABLE 3: In vitro cytotoxicity of isolated compounds from the combined fractions CSPE4/CSPE5.

\begin{tabular}{lccc}
\hline & $\begin{array}{c}\mathrm{WI} 38 \\
\mathrm{IC}_{50}(\mu \mathrm{g} / \mathrm{ml})\end{array}$ & $\begin{array}{c}\mathrm{J} 774 \\
\mathrm{IC}_{50}(\mu \mathrm{g} / \mathrm{ml})\end{array}$ & $\begin{array}{c}\mathrm{IS} \\
\left(\mathrm{IC}_{50 \mathrm{WI} 8} / \mathrm{IC}_{50}\right. \\
\left.\mathrm{J}_{774}\right)\end{array}$ \\
\hline Compound 1 & $\begin{array}{c}19.24 \pm 0.55 \\
(4.51 \mu \mathrm{M})\end{array}$ & $\begin{array}{c}12.60 \pm 0.23 \\
(2.96 \mu \mathrm{M})\end{array}$ & $1.5^{* * *}$ \\
Mixture of & $16.50 \pm 0.24$ & $1.79 \pm 0.03$ & \\
compounds & $(3.6 \mu \mathrm{M})$ & $(0.39 \mu \mathrm{M})$ & $9.2^{* * *}$ \\
3a/3b & & & \\
Camptothecin & $0.175 \pm 0.08$ & $0.011 \pm 0.004$ & $15^{* * *}$ \\
\hline
\end{tabular}

Compound 1: lupeol; mixture of compounds 3a/3b: 25-hydroperoxycycloart23 -en-3 $\beta$-ol and 24 -hydroperoxycycloart- 25 -en- $3 \beta$-ol; camptothecin: positive control; results are expressed as mean \pm standard error of the mean (SEM) of six determinations and activity differences between cell lines are statistically defined for each compound with the Mann-Whitney or Wilcoxon signed-rank tests for comparison to the highest tested concentration $\left(p<0.005^{* * *}\right)$.

WI38 cell line (selectivity index $=1.5$ ). On the other side, the mixture of 25 -hydroperoxycycloart-23-en-3 $\beta$-ol and 24hydroperoxycycloart-25-en-3 $\beta$-ol showed the highest activity on $\mathrm{J} 774$ cell line $\left(\mathrm{IC}_{50}=1.79 \mu \mathrm{g} / \mathrm{ml}\right)$ and showed a very interesting selectivity index $\left(\mathrm{IC}_{50}=16.50 \mu \mathrm{g} / \mathrm{ml}\right.$ on WI38, selectivity index $=9.2$ ).

3.5. Antimicrobial Activity of Partitions of Cirsium scabrum Leaves. In our previous screening conducted on 8 extremophile plants, the crude methanolic extract of $C$. scabrum did not show relevant antimicrobial activity [9]. However, due to the known antimicrobial activity of some Cirsium species [7], we decided to analyze again the crude methanolic extract as well as partitions of C. scabrum for their antimicrobial activity against a new panel of 36 pathogenic microorganisms including new Staphylococcus strains and Dermabacter hominis strains. Table 4 gives MIC (Minimum Inhibitory Concentration) values of the two active partitions: CSEA and CSBt. CSRW, CSPE, CSMC, and CSW were not considered active because they showed MIC values $>1000 \mu \mathrm{g} / \mathrm{ml}$. CSEA and CSBt showed a moderate antibacterial activity against 6 Staphylococcus aureus and 2 Dermabacter hominis strains with higher MIC values for the CSBt partition $(312 \mu \mathrm{g} / \mathrm{ml})$.

3.6. Identification of the Major Compounds of the CSBt Partition. A rapid phytochemical screening revealed that CSBt partition is rich in flavonoids and tannins. HPLC analysis of CSBt partition revealed the presence of two major compounds isolated by preparative HPLC. Structural elucidation was achieved based on their spectroscopic data $\left({ }^{1} \mathrm{H}\right.$ and ${ }^{13} \mathrm{C}$ NMR, 2D NMR experiments and HRMS) and by comparison with the literature. Compounds $4 \mathbf{a}$ and $\mathbf{4 b}$ were identified as a $(1: 1)$ mixture of luteolin 7-O- $\beta$-D-glucuronide (4a) [19] and luteolin 7-O- $\beta$-D-glucoside (4b) [20] and compound 5 was identified as apigenin 7-O- $\beta$-D-glucuronide [21] (Figure 1).

\section{Discussion}

In a previous study conducted on extremophile plants, we analyzed the antiproliferative activity of eight species using the MTT assay on J774 cancerous cell line compared to the one on WI38 noncancerous cell line. We highlighted that the crude methanolic extract of C. scabrum leaves (CSRW), a non investigated thistle, showed the highest activity on J774 cell line among other plant extracts tested and a good selectivity index [9]. In this current study, we aimed to investigate the cytotoxic activity of partitions obtained from the extract of C. scabrum leaves (CSRW) on the same cell lines. We showed that the petroleum ether partition (CSPE) was the most cytotoxic against the J774 cell line and may contain the compounds mostly responsible for the cytotoxic activity of this species. A bioguided fractionation of CSPE partition allowed us to identify these compounds, a $(1: 1)$ mixture of two hydroperoxide cycloartane-type triterpenoids: 25 -hydroperoxycycloart-23-en-3 $\beta$-ol (3a) and 24hydroperoxycycloart-25-en-3 $\beta$-ol (3b). Lee et al. [16] have previously isolated these compounds from the methylene chloride extract of Cirsium setidens aerial parts in three steps by successive column chromatography. They demonstrated that both compounds have significant cytotoxic activity against several cultured human cancer cell lines, in particular the 24-hydroperoxycycloart-25-en-3 $\beta$-ol. In our study, both compounds were isolated as a $(1: 1)$ mixture in one step from the most active combined fractions (CSPE4 and CSPE5) using CPC. The attempts to separate these compounds from each other by column chromatography were not fruitful because they rapidly degrade. Consequently, we tested the antiproliferative activity of the mixture. The cytotoxic activity described in the literature for some Cirsium species is not only attributed to cycloartane-type triterpenoids. Other studies highlighted the cytotoxic potential of other types of compounds, for example, caryolane-type sesquiterpenes from Cirsium souliei [6] or a nor- $\alpha$-tocopheroid ( $\alpha$-tocospiro C) from Cirsium setosum [22]. We also isolated from the CSPE partition of Cirsium scabrum leaves two common triterpenoids lupeol and taraxasterol acetate. Lupeol and taraxasterol acetate were identified in other Cirsium species (C. canum, C. hypoleucum, and C. oleraceum) [7]. Lupeol is a triterpenoid widely distributed in various botanical families. Several in vitro and preclinical animal studies suggest that lupeol has a wide range of biological activities, including anti-inflammatory, antimicrobial, antiprotozoal, cholesterol lowering, antiproliferative, anti-invasive, and antiangiogenic ones [18]. This natural product is able to modulate different molecular mechanisms contributing to the melanoma development $[23,24]$. Taraxasterol acetate is occurring in various Cirsium species [7]. For instance, this triterpenoid was isolated from a cytotoxic petroleum ether fraction of Cirsium setosum [25] or from Cirsium species growing in Turkey [26]. In general, it is quite common in the Asteraceae family $[27,28]$.

On the other hand, we evaluated the antibacterial activity of the crude methanolic extract and partitions of Cirsium scabrum against a panel of 36 Gram-positive and Gramnegative bacteria. The crude extract showed no activity, 
TABLE 4: Antimicrobial activity of active partitions of C. scabrum leaves.

\begin{tabular}{|c|c|c|c|c|c|}
\hline & \multicolumn{2}{|c|}{$\begin{array}{l}\text { Active partitions } \\
\text { MIC values }(\mu \mathrm{g} / \mathrm{ml})\end{array}$} & \multicolumn{3}{|c|}{$\begin{array}{l}\text { Reference antibiotics } \\
\text { MIC values }(\mu \mathrm{g} / \mathrm{ml})\end{array}$} \\
\hline & CSBt & CSEA & Amox & Gent & Vanc \\
\hline \multicolumn{6}{|l|}{ Gram - bacteria } \\
\hline Escherichia coli $\mathrm{T} 20 \mathrm{~A} 2$ & NA & NA & $S$ & $\mathrm{R}$ & $\mathbf{R}$ \\
\hline Pseudomonas aeruginosa $\mathrm{T} 41$ & NA & NA & $\mathrm{R}$ & S & $\mathrm{R}$ \\
\hline Pseudomonas aeruginosa ATCC 9027 & NA & NA & $\mathrm{R}$ & S & $\mathrm{R}$ \\
\hline \multicolumn{6}{|l|}{ Gram + bacteria } \\
\hline Dermabacter hominis T47A7 & 312 & 625 & $\mathrm{R}$ & $\mathrm{S}$ & $\mathrm{S}$ \\
\hline Dermabacter hominis T49B5 & 312 & 625 & S & S & S \\
\hline Corynebacterium striatum T40A3 & NA & NA & $\mathrm{R}$ & $\mathrm{R}$ & $S$ \\
\hline Corynebacterium striatum T46C1 & NA & NA & S & S & S \\
\hline Enterococcus faecalis T37B1 & NA & NA & S & S & S \\
\hline Enterococcus faecalis T47A16 & NA & NA & $\mathrm{R}$ & $S$ & S \\
\hline Streptococcus agalactiae T53A4 & NA & NA & $\mathrm{R}$ & $\mathrm{R}$ & $\mathrm{R}$ \\
\hline Staphylococcus aureus T2510 & 312 & 625 & $\mathrm{R}$ & S & $\mathrm{S}$ \\
\hline Staphylococcus aureus T281 & NA & NA & $\mathrm{R}$ & S & S \\
\hline Staphylococcus aureus 8143 & 312 & 625 & S & S & S \\
\hline Staphylococcus aureus 8148 & 312 & 625 & $\mathrm{R}$ & S & S \\
\hline Staphylococcus aureus 8142 & NA & NA & $\mathrm{R}$ & S & S \\
\hline Staphylococcus aureus T61 & NA & NA & $\mathrm{R}$ & S & S \\
\hline Staphylococcus aureus T21 & 312 & 625 & $\mathrm{R}$ & S & S \\
\hline Staphylococcus aureus T11 & NA & NA & $\mathrm{R}$ & S & S \\
\hline Staphylococcus aureus T306 & 312 & 625 & $\mathrm{~S}$ & $\mathrm{~S}$ & $\mathrm{~S}$ \\
\hline Staphylococcus aureus T26A4 & 625 & 625 & $\mathrm{R}$ & S & $\mathrm{S}$ \\
\hline Staphylococcus epidermidis T151 & NA & NA & $\mathrm{R}$ & $\mathrm{R}$ & S \\
\hline Staphylococcus epidermidis T19A1 & NA & NA & $S$ & $S$ & $\mathrm{R}$ \\
\hline Staphylococcus capitis T21A3 & NA & NA & S & S & S \\
\hline Staphylococcus capitis T29A2 & NA & NA & S & S & S \\
\hline Staphylococcus pettenkoferi T282 & NA & NA & S & S & $S$ \\
\hline Staphylococcus pettenkoferi T33 & NA & NA & $\mathrm{R}$ & S & S \\
\hline Staphylococcus saprophyticus 8237 & NA & NA & $S$ & $S$ & S \\
\hline Staphylococcus lugdunensis T36A1 & NA & NA & S & S & $\mathrm{S}$ \\
\hline Staphylococcus lugdunensis T47B2 & NA & NA & $\mathrm{S}$ & $\mathrm{S}$ & $\mathrm{S}$ \\
\hline
\end{tabular}

MIC ( $\mu \mathrm{g} / \mathrm{ml}$ ) of positive controls: Amox (amoxicillin), S: $\leq 4$, R: $>16$, Gent (gentamicin), S: $\leq 4, \mathrm{R}:>8$; Vanc (vancomycin), S: $\leq 4, \mathrm{R}:>16$; MIC $(\mu \mathrm{g} / \mathrm{ml})$ of partitions (CSBt: C. scabrum leaves butanol partition; CSEA: C. scabrum leaves ethyl acetate partition): MIC $<100 \mu \mathrm{g} / \mathrm{ml}$ : high activity; $100 \mu \mathrm{g} / \mathrm{ml}<\mathrm{MIC}<$ $500 \mu \mathrm{g} / \mathrm{ml}:$ moderate activity; $500 \mu \mathrm{g} / \mathrm{ml}<$ MIC $<1000 \mu \mathrm{g} / \mathrm{ml}$ : low activity; MIC $>1000 \mu \mathrm{g} / \mathrm{ml}: \mathrm{NA}=$ inactive.

while the butanol partition CSBt had a moderate action against 6 Staphylococcus aureus strains and 2 Dermabacter hominis strains. We isolated the major compounds of the CSBt partition, a $(1: 1)$ mixture of luteolin $7-O-\beta$-Dglucuronide and luteolin $7-O-\beta$-D-glucoside (compounds $\mathbf{4 a}$ and $\mathbf{4 b}$ ) and apigenin $7-O-\beta$-D-glucuronide (compound 5 ), as a primary approach to understand the antibacterial potential of C. scabrum. To our knowledge, literature does not describe or little describes the antibacterial activity of luteolin $7-O-\beta$-D-glucuronide and apigenin $7-O-\beta$-D-glucuronide. However, it is worth mentioning that some plant species containing these two flavones showed antibacterial activity against some Gram-positive and Gram-negative bacteria, including Staphylococcus aureus strains $[29,30]$. On the other hand, luteolin 7-O- $\beta$-D-glucoside (cynaroside) demonstrated antibacterial activity especially against Gram-negative bacteria [31]. This flavone was already identified in Cirsium japonicum [32]. In general, flavonoids are well known to be effective antibacterial substances against a wide array of bacteria, with MIC in the range of 0.06 to $31.3 \mu \mathrm{g} / \mathrm{ml}$ against some Gram-positive bacteria and 0.3 to $39.1 \mu \mathrm{g} / \mathrm{ml}$ against some Gram-negative bacteria, for the ten most potently antibacterial natural flavonoids tested in recent years [33]. As a matter of fact, they are synthesized by plants in response to microbial infection [34]. The mechanism of antimicrobial action of flavonoids seems to be complex as it does not target 
one specific site of action. In addition to direct and synergistic antibacterial effects, flavonoids interfere with bacterial virulence factors, including quorum-sensing signal receptors, some enzymes, and toxins [33]. The antibacterial activity of apigenin and luteolin against Staphylococcus aureus was thoroughly investigated. Apigenin can remarkably decrease at low concentrations the production of $\alpha$-hemolysin, a toxin released by $S$. aureus. Also, apigenin has a therapeutic effect on $S$. aureus-related pneumonia by alleviating injury of the lung tissue and decreasing cytokine levels [35]. Concerning luteolin, Wang and Xie [36] suggested that this flavone could inhibit the activity of DNA topoisomerases I and II, which results in some decrease in the nucleic acid and protein synthesis. A recent study has investigated the mechanism of action of luteolin against methicillin-resistant Staphylococcus aureus (MRSA) [37]. The authors showed that luteolin acts in synergy by increasing cytoplasmic membrane permeability and inhibiting ATPase. The study also suggests a direct binding of luteolin with the major constituent of the $S$. aureus cell wall. The antibacterial activity of flavonoids against $D$. hominis was not reported in the literature so far. Besides, little or no information exists on the activity of natural products from plants against this bacteria strain. D. hominis is a common colonizer from human skin. It is usually susceptible to vancomycin, teicoplanin, and linezolid [38]. Further phytochemical investigation of the butanol partition of C. scabrum would deepen the understanding of its activity against $D$. hominis strains. On the other hand, the antibacterial activity of CSBt partition could be also attributed to the presence of tannins. The antimicrobial activity of tannins is widely investigated. The different mechanisms proposed to explain their mechanism of action include direct action on microbial metabolism but also inhibition of extracellular microbial enzymes or deprivation of the substrates required for microbial growth [39]. Nazaruk et al. [40] reported the presence of tannins in aqueous extracts from leaves of several Cirsium species. They showed that most of these extracts had antibacterial potential. Although they suggested that the content of small-molecular phenolic compounds had greater influence on the activity of extracts than tannins, consideration will be given to investigate more the antibacterial effect of the CSBt partition from C. scabrum.

\section{Conclusion}

A phytochemical and biological study was carried out for the first time on Cirsium scabrum. The study revealed that the crude methanolic extract of the leaves and more precisely the petroleum ether partition (CSPE) showed an interesting and quite selective cytotoxic potential against the J774 cell line. A mixture of two hydroperoxide cycloartane-type triterpenoids was isolated and identified as the secondary metabolites responsible for this activity. Two other triterpenoids, lupeol and taraxasterol acetate, were also isolated from the CSPE partition, strengthening our knowledge about the chemical composition of Cirsium scabrum. We also focused our study on the antibacterial potential of this species. The butanol partition of C. scabrum leaves (CSBt) showed a moderate activity against 6 Staphylococcus aureus strains and 2 Dermabacter hominis strains. The two major compounds of CSBt partition were identified as glycosides of flavones, suggesting that they might be responsible for this activity, as well as the presence of tannins.

\section{Conflicts of Interest}

The authors declare that they have no conflicts of interest.

\section{Acknowledgments}

This study was supported by internal financial support from the Charles Viollette Institute. The authors wish to thank platforms of CUMA (University of Lille 2, Professor J. F. Goossens) and LARMN (University of Lille 2, Professor N. Azaroual) for access to equipment. The authors are also grateful to Laurence Marcourt for her technical assistance concerning the identification of compound 2 . The School of Pharmaceutical Sciences of the University of Geneva (Professor J.-L. Wolfender) is grateful in this context to the Swiss National Science Foundation for the support in the acquisition of the NMR $600 \mathrm{MHz}$ (SNF R'Equip Grant 316030_164095). The authors also wish to thank Dr. Abderrazak Smaoui (Biotechnology Centre of Borj-Cédria), Maude Bourlet (UCL), Laetitia Bocquet, Moussa Diop, Jennifer Samaillie, Séverine Mahieux, and Dr. Mostafa Kouach (University of Lille 2) for their skillful technical assistance.

\section{References}

[1] D. J. Mabberley, Mabberley's Plant Book: A Portable Dictionary of Plants, their Classification and Uses, Cambridge University Press, Cambridge, UK, 3 edition, 2008.

[2] D. S. Khramova, V. V. Golovchenko, A. S. Shashkov, D. Otgonbayar, A. Chimidsogzol, and Y. S. Ovodov, "Chemical composition and immunomodulatory activity of a pectic polysaccharide from the ground thistle Cirsium esculentum Siev," Food Chemistry, vol. 126, no. 3, pp. 870-877, 2011.

[3] I. Demirtas, A. R. Tufekci, A. S. Yaglioglu, and M. Elmastas, "Studies on the antioxidant and antiproliferative potentials of Cirsium arvense subsp. vestitum," Journal of Food Biochemistry, vol. 41, Article ID e12299, 2016.

[4] R. S. Vizgirdas and E. M. Rey-Vizgirdas, Wild Plants of the Sierra Nevada, University of Nevada Press, Reno, Nev, USA, 2009.

[5] P. M. Guarrera, "Traditional phytotherapy in Central Italy (Marche, Abruzzo, and Latium)," Fitoterapia, vol. 76, no. 1, pp. $1-25,2005$.

[6] X.-F. He, Z.-W. He, X.-J. Jin et al., "Caryolane-type sesquiterpenes from Cirsium souliei," Phytochemistry Letters, vol. 10, no. 1, pp. 80-85, 2014.

[7] I. E. Jordon-Thaden and S. M. Louda, "Chemistry of Cirsium and Carduus: A role in ecological risk assessment for biological control of weeds?" Biochemical Systematics and Ecology, vol. 31, no. 12, pp. 1353-1396, 2003.

[8] I. Demirtas, A. R. Tufekci, A. S. Yaglioglu, and M. Elmastas, "Studies on the antioxidant and antiproliferative potentials of Cirsium arvense subsp. vestitum," Journal of Food Biochemistry, vol. 41, no. 1, 2016.

[9] R. Sahli, C. Rivière, C. Neut et al., "An ecological approach to discover new bioactive extracts and products: the case of 
extremophile plants," Journal of Pharmacy and Pharmacology, vol. 69, no. 8, pp. 1041-1055, 2017.

[10] A. Berthod, M. Hassoun, and M. J. Ruiz-Angel, "Alkane effect in the Arizona liquid systems used in countercurrent chromatography," Analytical and Bioanalytical Chemistry, vol. 383, no. 2, pp. 327-340, 2005.

[11] J. Bero, H. Ganfon, M.-C. Jonville et al., "In vitro antiplasmodial activity of plants used in Benin in traditional medicine to treat malaria," Journal of Ethnopharmacology, vol. 122, no. 3, pp. 439444, 2009.

[12] S. Mahamodo, C. Rivière, C. Neut et al., "Antimicrobial prenylated benzoylphloroglucinol derivatives and xanthones from the leaves of Garcinia goudotiana," Phytochemistry, vol. 102, pp. 162-168, 2014.

[13] R. B. Badisa, S. F. Darling-Reed, P. Joseph, J. S. Cooperwood, L. M. Latinwo, and C. B. Goodman, "Selective cytotoxic activities of two novel synthetic drugs on human breast carcinoma MCF7 cells," Anticancer Research, vol. 29, no. 8, pp. 2993-2996, 2009.

[14] S. B. Mahato and A. P. Kundu, " ${ }^{13}$ C NMR Spectra of pentacyclic triterpenoids-a compilation and some salient features," Phytochemistry, vol. 37, no. 6, pp. 1517-1575, 1994.

[15] L. M. Khalilov, A. Z. Khalilova, E. R. Shakurova et al., "PMR and ${ }^{13} \mathrm{C}$ NMR spectra of biologically active compounds. XII. Taraxasterol and its acetate from the aerial part of Onopordum acanthium," Chemistry of Natural Compounds, vol. 39, no. 3, pp. 285-288, 2003.

[16] W. B. Lee, C. K. Hak, R. C. Ock et al., "Phytochemical constituens of Cirsium setidens nakai and their cytotoxicity against human cancer cell lines," Archives of Pharmacal Research, vol. 25, no. 5, pp. 628-635, 2002.

[17] T. Kato, B. Frei, M. Heinrich, and O. Sticher, "Antibacterial hydroperoxysterols from Xanthosoma robustum," Phytochemistry, vol. 41, no. 4, pp. 1191-1195, 1996.

[18] A. Wal, A. Rai, P. Wal, and G. Sharma, "Biological activities of lupeol," Systematic Reviews in Pharmacy, vol. 2, no. 2, p. 96, 2011.

[19] A. Dapkevicius, T. A. Van Beek, G. P. Lelyveld et al., "Isolation and structure elucidation of radical scavengers from Thymus vulgaris leaves," Journal of Natural Products, vol. 65, no. 6, pp. 892-896, 2002.

[20] A. Mulkens and I. Kapetanidis, "Flavonoids of the leaves of Melissa officinalis L. (Lamiaceae)," Pharmaceutica Acta Helvetiae, vol. 62, no. 1, pp. 19-22, 1987.

[21] G. Flamini, E. Antognoli, and I. Morelli, "Two flavonoids and other compounds from the aerial parts of Centaurea bracteata from Italy," Phytochemistry, vol. 57, no. 4, pp. 559-564, 2001.

[22] Z. Yuan, H. Duan, Y. Xu et al., " $\alpha$-Tocospiro C, a novel cytotoxic $\alpha$-tocopheroid from Cirsium setosum," Phytochemistry Letters, vol. 8, no. 1, pp. 116-120, 2014.

[23] A. Gajos-Michniewicz and M. Czyz, "Modulation of WNT/ $\beta$ catenin pathway in melanoma by biologically active components derived from plants," Fitoterapia, vol. 109, pp. 283-292, 2016.

[24] L. R. Strickland, H. C. Pal, C. A. Elmets, and F. Afaq, “Targeting drivers of melanoma with synthetic small molecules and phytochemicals," Cancer Letters, vol. 359, no. 1, pp. 20-35, 2015.

[25] L. Li, Z. Sun, and X. Shang, "Triterpene Compounds From Cirsium setosum," Zhongguo Zhong Yao Za Zhi, vol. 37, no. 7, pp. 951-955, 2012.

[26] M. Boğa, P. K. Yilmaz, D. B. Cebe, M. Fatima, S. Siddiqui, and U. Kolak, "Chemical constituents and biological activities of Cirsium leucopsis, C. sipyleum, and C. eriophorum," Zeitschrift fur Naturforschung-Section C Journal of Biosciences, vol. 69, no. 9-10, pp. 381-390, 2014.

[27] J. Zhao, D. Evangelopoulos, S. Bhakta, A. I. Gray, and V. Seidel, "Antitubercular activity of Arctium lappa and Tussilago farfara extracts and constituents," Journal of Ethnopharmacology, vol. 155, no. 1, pp. 796-800, 2014.

[28] P. Ramos, Â. Guerra, O. Guerreiro et al., "Antiproliferative effects of Cynara cardunculus L. var. altilis (DC) Lipophilic extracts," International Journal of Molecular Sciences, vol. 18, no. 1, p. 63, 2017.

[29] S. O. Salawu, A. O. Ogundare, B. B. Ola-Salawu, and A. A. Akindahunsi, "Antimicrobial activities of phenolic containing extracts of some tropical vegetables," African Journal of Pharmacy and Pharmacology, vol. 5, no. 4, pp. 486-492, 2011.

[30] F. Moussaoui, A. Zellagui, N. Segueni, A. Touil, and S. Rhouati, "Flavonoid constituents from Algerian Launaea resedifolia (O.K.) and their antimicrobial activity," Records of Natural Products, vol. 4, no. 1, pp. 91-95, 2010.

[31] L. Žemlička, P. Fodran, V. Lukeš et al., "Physicochemical and biological properties of luteolin-7-O- $\beta$-d- glucoside (cynaroside) isolated from Anthriscus sylvestris (L.) Hoffm," Monatshefte fur Chemie, vol. 145, no. 8, pp. 1307-1318, 2014.

[32] W.-C. Lee, H. A. Jung, J. S. Choi, Y. S. Kim, and S.-M. Lee, "Protective effects of luteolin against apoptotic liver damage induced by D-galactosamine/lipopolysaccharide in mice," Journal of Natural Products, vol. 74, no. 9, pp. 1916-1921, 2011.

[33] T. P. T. Cushnie and A. J. Lamb, "Recent advances in understanding the antibacterial properties of flavonoids," International Journal of Antimicrobial Agents, vol. 38, no. 2, pp. 99-107, 2011.

[34] R. A. Dixon, P. M. Dey, and C. J. Lamb, "Phytoalexins: enzymology and molecular biology," Advances in Enzymology and Related Areas of Molecular Biology, vol. 55, pp. 1-136, 1983.

[35] J. Dong, J. Qiu, J. Wang et al., "Apigenin alleviates the symptoms of Staphylococcus aureus pneumonia by inhibiting the production of alpha-hemolysin," FEMS Microbiology Letters, vol. 338, no. 2, pp. 124-131, 2013.

[36] Q. Wang and M. Xie, "Antibacterial activity and mechanism of luteolin on Staphylococcus aureus," Wei Sheng Wu Xue Bao, vol. 50, no. 9, pp. 1180-1184, 2010.

[37] D.-K. Joung, Y.-S. Lee, S.-H. Han et al., "Potentiating activity of luteolin on membrane permeabilizing agent and ATPase inhibitor against methicillin-resistant Staphylococcus aureus," Asian Pacific Journal of Tropical Medicine, vol. 9, no. 1, pp. 19-22, 2016.

[38] I. Fernández-Natal, J. A. Sáez-Nieto, M. J. Medina-Pascual et al., "Dermabacter hominis: a usually daptomycin-resistant grampositive organism infrequently isolated from human clinical samples," New Microbes and New Infections, vol. 1, no. 3, Article ID 50031, pp. 35-40, 2013.

[39] A. Scalbert, "Antimicrobial properties of tannins," Phytochemistry, vol. 30, no. 12, pp. 3875-3883, 1991.

[40] J. Nazaruk, S. K. Czechowska, R. Markiewicz, and M. H. Borawska, "Polyphenolic compounds and in vitro antimicrobial and antioxidant activity of aqueous extracts from leaves of some Cirsium species," Natural Product Research, vol. 22, no. 18, pp. 1583-1588, 2008. 


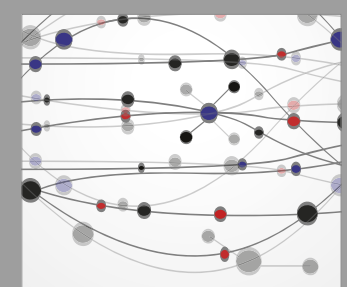

The Scientific World Journal
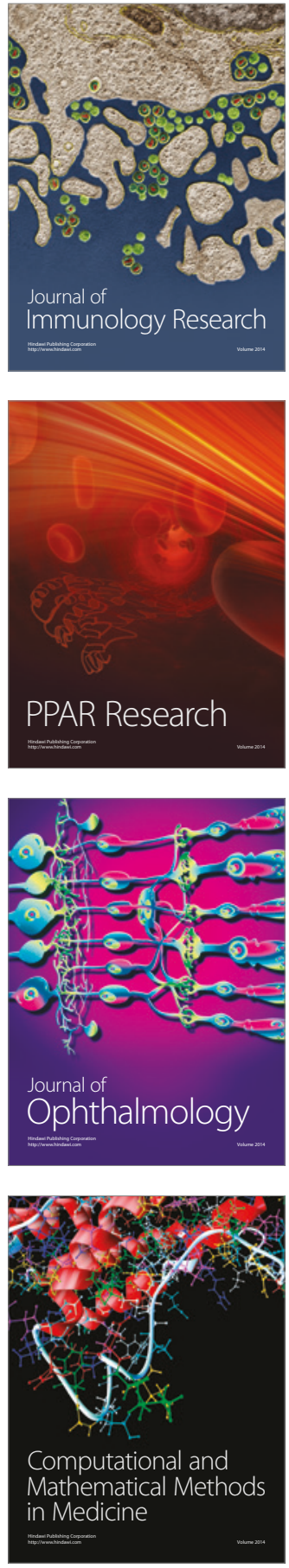

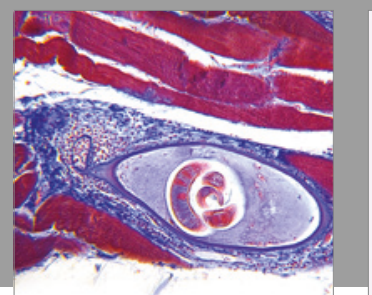

Gastroenterology Research and Practice
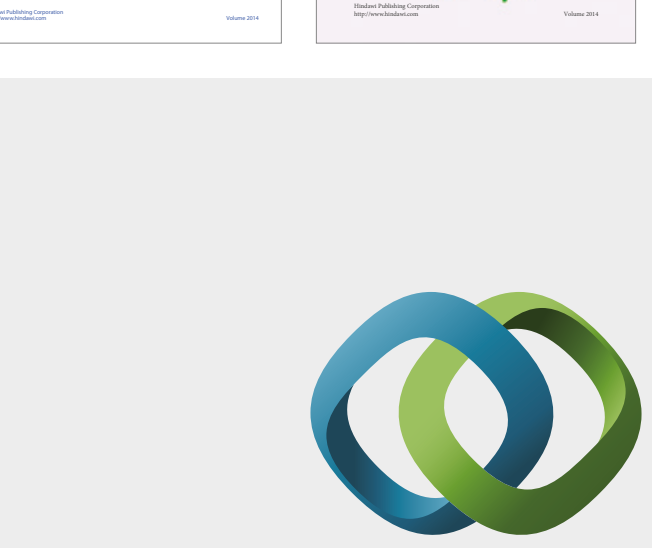

\section{Hindawi}

Submit your manuscripts at

https://www.hindawi.com
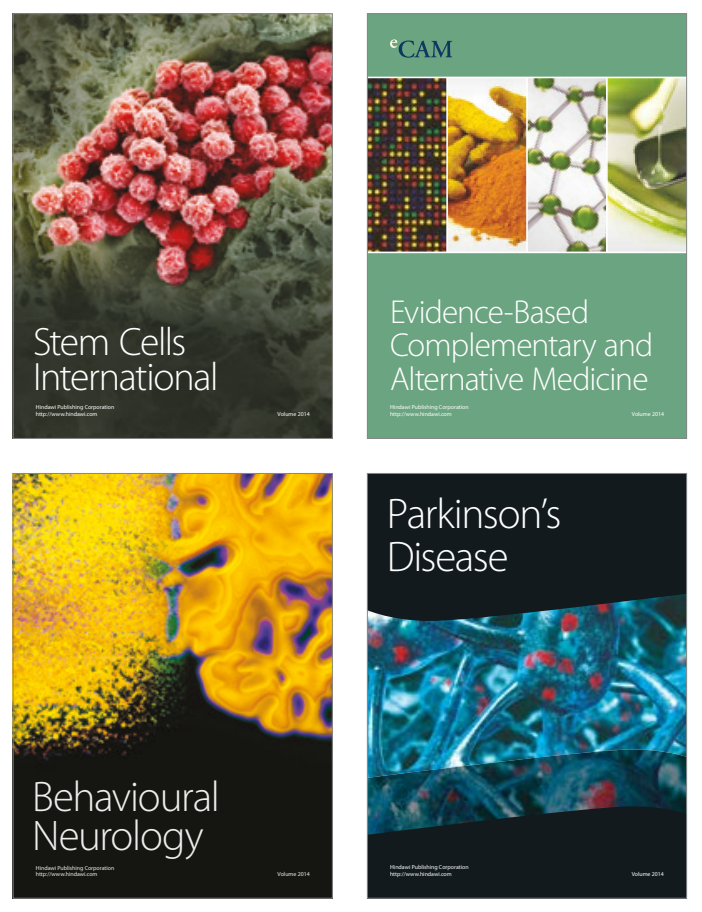
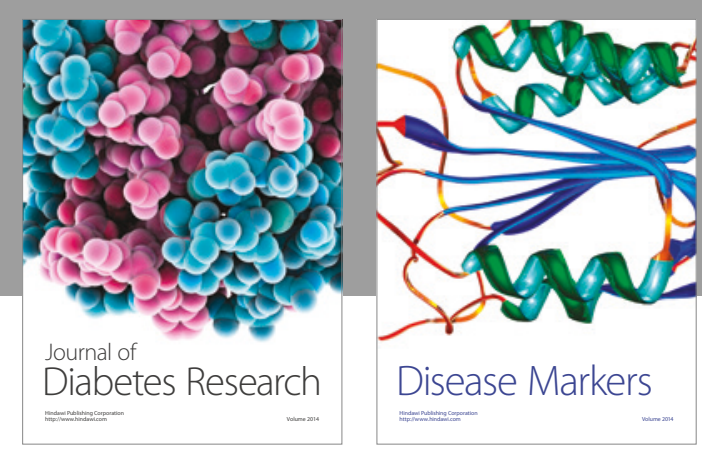

Disease Markers
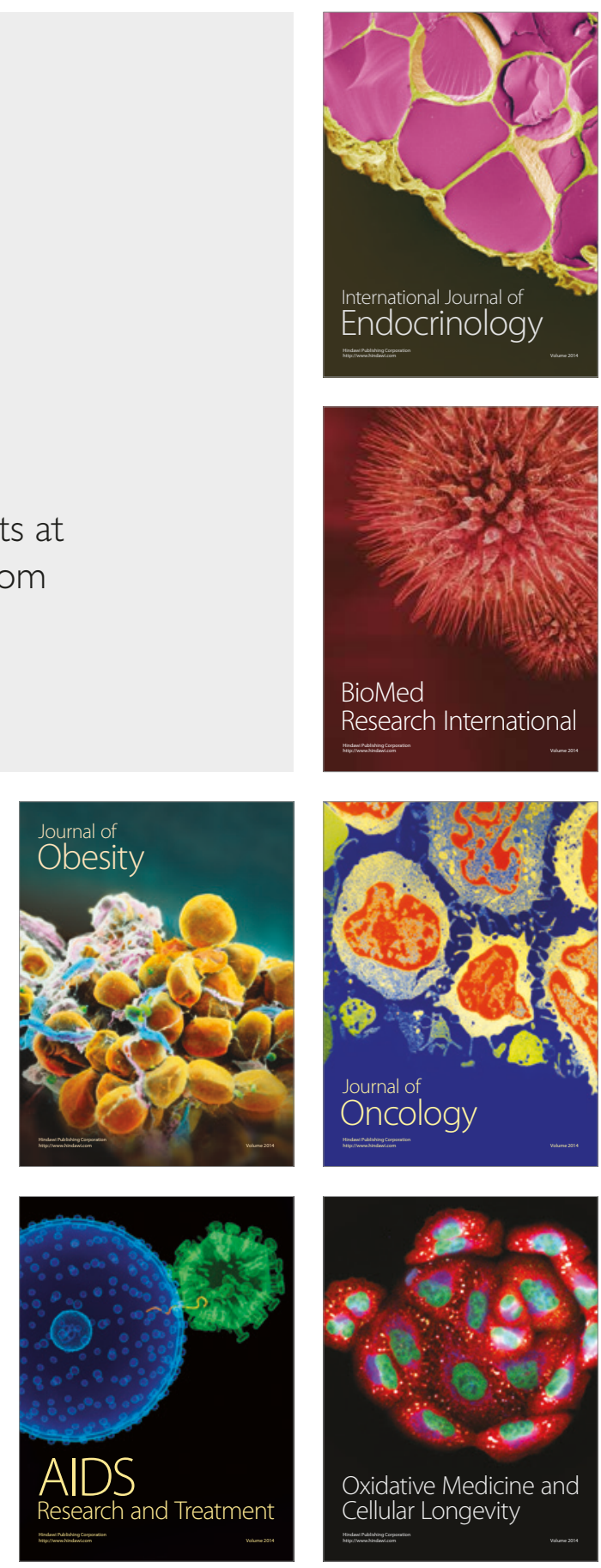